\title{
Faster, harder, longer, stronger - management at the threshold between work and private life: The case of work place health promotion
}

\section{Christian Maravelias}

To cite this article: Christian Maravelias (2016): Faster, harder, longer, stronger - management at the threshold between work and private life: The case of work place health promotion, Culture and Organization, DOI: 10.1080/14759551.2016.1141414

To link to this article: http://dx.doi.org/10.1080/14759551.2016.1141414

曲 Published online: 04 Mar 2016.

Submit your article to this journal $\pi$

Џll Article views: 24

Q View related articles $\longleftarrow$

View Crossmark data \lceil 


\title{
Faster, harder, longer, stronger - management at the threshold between work and private life: The case of work place health promotion
}

\author{
Christian Maravelias
}

Stockholm Business School, Stockholm University, Stockholm, Sweden

This paper studies Work Place Health Promotion at two international corporations as an example of an unobtrusive control that targets employees' lifestyles. It uses Michel Foucault's concepts of neoliberal governmentality and post-disciplinary control to show how Work Place Health Promotion breaks with the disciplinary logic of control most commonly associated with studies of unobtrusive controls in organizations. While discipline is centripetal, correcting employees' misconduct so that they freely keep within prescribed norms, Work Place Health Promotion is centrifugal, targeting employees' lifestyles and promoting those existing faculties and inclinations that may increase their activity, performance and their health. It hereby emerges as less restrictive than organizational discipline, but also as more discriminating. For not only does it subject employees' lifestyles to an economic logic of investment and disinvestment, it also contributes to an exclusion of employees that fail in this regard in the name of their lack of health.

\section{ARTICLE HISTORY}

Received 16 April 2013

Accepted 15 December 2015

\section{KEYWORDS}

Work place health promotion; neoliberal governmentality; disciplinary control; post-disciplinary control

\section{Introduction}

Sociological studies has suggested that the turn to neoliberalism in the 1980s has implicated a shift in the principles of governing individuals and populations, away from disciplinary regulation towards an 'enterprise culture' (e.g. Dean 1999; Gordon 1991; Lemke 2001; Miller and Rose 2008; Rose 1999). Drawing on Foucault's later works on liberalism and neoliberalism $(2003,2007,2009)$, this literature has studied discourses and techniques of governing such as precarious employments, audit mechanisms and quasi markets to show how the turn to enterprise implies an idealization of a new type of individual. Rather than the disciplined individual, who freely subjects to circumscribed norms and ideals, an enterprising self is idealized that does not repress her inner most desires, but manages to put her whole self to productive work (Dean 1999; Lazzarato 2009; McNay 2009; O'Malley 2000).

In the literature on organizational control the idea of a shift towards neoliberalism and enterprise is associated with studies of Human Resource Management (HRM), corporate culture, teamwork, etc. as examples of new unobtrusive forms of management. Characteristic for these forms of control, it has typically been found, is that they do not seek to regulate employees' behaviour directly. Instead they seek to make up self-governing employees by regulating their identities (e.g. Alvesson, Ashcraft, and Thomas 2008; Alvesson and Willmott 2002; Collinson 2003; Fleming 2014; Kuhn 2006; Willmott 2005).

While notions of enterprise and neoliberalism have been generally acknowledged by this 'identity regulation' literature, the idea that those notions associate with a shift away from disciplinary principles of control has received limited attention (Barratt 2008; Fleming 2014; Munro 2012). Quite 
the contrary, conceptually the identity regulation literature has been strongly influenced by Foucault's work on disciplinary power (1977), which has been used to demonstrate how identity regulation implies a form of power, which is intimately intertwined with employee's own efforts to create a coherent sense of self (Knights and Willmott 1989). Hence, the notion of discipline has opened possibilities of analysing discourses and techniques such as HRM and corporate culture in ways that breach the conventional dualism between structure and agency (cf. Alvesson and Willmott 2002; Willmott 2005). The idea is then that such managerial discourses potentially align employees' identity work with instrumental goals, not by force or domination, but by empowering employees with discursive resources for their self-surveillance and normalization (e.g. Alvesson 2000; Knights and Willmott 1989; Sewell and Wilkinson 1992).

For instance in Barker's (1993) and Kunda's (1992) studies of corporate culture it is shown how ostensibly warmer, value-based methods of management result in peer-control, self-surveillance and a self-disciplining of individual identities that are strenuously strategized to fit the norms and ideals of the organization. Similarly, in studies of HRM, techniques such as attitude surveys, assessment centres, 360 interviews, mentorship programmes, etc., (Bergström and Knights 2006; Covaleski et al. 1998; Deetz 1998; Townley 1994) are suggested to make employees manageable by making them avow their views on work, their careers and their ambitions. In line with Foucault's (1977) concept of discipline, employees manageability are then seen to derive not only or even primarily from that managers are given access to the 'truth' that HRM reveals about the level and appropriateness of their skills, characteristics and motivations, but also from that employees (especially since they know that that they are potentially observed and examined) gradually internalize this 'truth' and manage themselves in accordance with it (Covaleski et al. 1998; Townley 1994). In Townley's (1994) words, HRM disciplines by 'objectifying' and 'subjectifying' employees.

However, in line with the sociological studies referred to above (e.g. Dean 1999; McNay 2009), more and more studies of organizational control have begun to report how the turn to neoliberalism and enterprise culture creates forms of work and managerial idealizations of employees' that in certain respects cannot be captured by the disciplinary framework. Kunda and Ailon-Souday (2005) for instance report how the spread of project work and temporary employments have led human resource managers to abandon the ambition of disciplining employees to conform to a pre-fabricated culture. Not only is it alleged of being too difficult to achieve, it is also seen to potentially stifle employees' motivation and initiative. Instead, Kunda and Ailon-Souday (2005) reports, human resource managers have begun to encourage employees to be 'plain' and 'true', expressing their everyday self on the job. Similarly, Fleming $(2014,878)$ observes how call-centres and advertising agencies encourage employees to 'be themselves' because they are then 'more likely to voluntarily enact "the buzz of life" in tasks that increasingly require interpersonal virtuosity, authenticity ... and self-organized know-how'. Munro and Weiskopf $(2011,2)$ find similar examples at large multinational companies such as SAP, TNT, Express Germany and Austrian Telecom, where 'the creativity and subjectivity of employees is seen as a resource to be mobilized, rather than "moulded" into disciplined patterns of identity'. Kuhn (2006) refers to these changes as the development of a 'lifestyle approach to management'. Such an approach, he argues, is defined by its ambition of stimulating more engaged employee performances, on the one hand, by welcoming employees' everyday self on the job and, on the other hand, by encouraging employees to let work infiltrate and structure life beyond the formal workday. Munro (2012) takes one step further and argues that all these reports are signs of a forthcoming 'post-disciplinary' world of work, which is less reliant upon 'territorial confinement' of docile, normalized employees than on methods, which keep individuals active and in movement in all of life's spheres.

These studies suggest that the identity regulation literature has one limitation: While it has primarily focused on managerial discourses and techniques such as corporate culture or HRM, which hold on to and seek to maintain a relatively sharp distinction between work and life, non-work associates such as employees' lifestyles, every day selves, etc. begin to be seen as important resources that organizations seek to link to productive activity. This limitation relates to its analysis of new 
unobtrusive controls along the lines of Foucault's (1977) notion of discipline and the docile subjects it generates within secluded spaces. This analysis risks missing out on the neoliberal, enterprising aspects of these managerial practices, their associated forms of control and the subjects they idealize and seek to regulate (Barratt 2008; Munro 2012; Munro and Weiskopf 2011). Obviously, this is not to question Foucault's general post-structuralist notion that modern power operates not primarily via intransitive generative mechanisms such as 'the State' and 'Capital', but via discourses and techniques, which help produce subjectivities (cf. Willmott 2005). Yet, in relation to the changes reported in the studies referred to above, the specific disciplinary power/knowledge framework seems in part to prevent us from seeing how employees' personalities, lifestyles, creativity and competitive inclinations emerge in neoliberal contexts of partly open, networked organizations not as potential problems that need to be controlled, but as resources that should be mobilized (cf. Fleming and Sturdy 2011). As Foucault himself said, with neoliberalism 'control is no longer just the necessary counterweight to freedom, as in the case of panopticism, it becomes its mainspring' $(2009,67)$.

Generally, these studies indicate that there is a need for studies of discourses and techniques that transgress the work-life boundary and reflect an ambition of linking the whole individual to productive organizational activity. This paper attempts to take steps in that direction by means of a study of Work Place Health Promotion (henceforth WHP) in two corporate settings: among factory workers in a corporation producing trucks and buses and among researchers in an international Biotech company. The paper shows how WHP operates as an unobtrusive form of control that seeks to make employees at once healthier and professionally more successful by promoting improvement oriented and self-governed lifestyles. On this basis, the paper suggests that WHP is an interesting example of an unobtrusive control that binds together professional and private life in a performance-oriented relationship and contributes to legitimately extending managerial principles and values beyond the formal boundaries of work organizations.

In the analysis of WHP the paper draws on Foucault's later works on neoliberal governmentality and post-disciplinary control $(2003,2007,2009)$, on their further development by for instance Dean (1999), Gershon (2011), Gordon (1991), Lemke (2001), McNay (2009), O'Malley (2000) and Rose (1999) and on their more specific usage in studies of government and health (Dean 2015; Lakoff 2015; Rose 2007; Villadsen and Wahlberg 2015). Through this literature the paper develops the argument that WHP operates as an unobtrusive form of control, but in ways that break with the disciplinary logic of control most commonly associated with studies of identity regulation. In short, while the discipline associated with corporate culture programmes and HRM is centripetal, operating in a restricted space where it makes up docile employees that freely keep within prescribed normative limits, WHP illustrates a centrifugal post-disciplinary form of power that targets already existing parts of individuals' lifestyles, which are spontaneously motivating for the individual and which thus can help to propel the individual towards more activity and performance. Based on the study I argue that while the post-disciplinary form of control that WHP illustrates is less restrictive than conventional discipline it is also more discriminating; for by promoting individuals who are already healthy in the sense that they are willing and able to subordinate their lifestyles to performance criteria, they implicitly contribute to the exclusion of those that fail in these regards in the name of their lack of health.

Below, I first develop the notions of neoliberal governmentality and post-disciplinary control and show in which specific respects these notions implicate a break with the disciplinary framework. Thereafter I account for the study of WHP. The paper is ended with a discussion and conclusions.

\section{Post-disciplinary regulation}

As is well known, Foucauldian analysis of control is not a matter of lamenting how the state, corporations or other institutions supress individuals' autonomy, it is a matter of investigating on the basis of which reflections and tactics and for the sake of which ends individuals' conducts are conducted (Dean 1999). This involves three closely linked dimensions (Rose 1996) which will structure my 
reasoning below: a political dimension captured by the term governmentality, which signifies the complex of ideas, calculations and strategies through which diverse authorities - big capital, political institutions, medical authorities, and so on - attempt to act on individuals and populations for the sake of achieving certain ends (health, entrepreneurialism, and so on); a technical dimension relating to the specific arrangements - factories, bureaucracies, networks, projects, etc., which put into play certain assumptions about what it means to be a particular human being - an employee, an entrepreneur, etc. - and that seeks to bring about orchestrated conduct that maximize certain capacities of individuals and constrain others in accordance with particular forms of expertise (health, profitability, and so on); finally, an ethical dimension understood in a practical sense as modes and techniques by which individuals act on and evaluate themselves.

Pivotal in the transition from a liberal to a neoliberal governmentality is neoliberalism's radical rethinking of the ontology of the market and homo oeconomicus (Foucault 2009; Mirowski 2013). Liberal governmentality draws on Smith's (1977/1776) view of the market and homo oeconomicus as natural phenomena, the autonomy of which the state should protect and enable but not interfere with other than by cautiously keeping their cold self-interested logic separate from the collectivistic logic of civil society (McNay 2009). The autonomy of homo oeconomicus is then to be secured by enabling (e.g. through public education) individuals to own their bodies and their capacities to labour as properties that they can sell on the labour market (Gershon 2011). Here discipline emerges as the technical institution of a liberal governmentality and the specific ethical practices it implies. Townley's (1994) and Covaleski et al.'s (1998) studies of identity regulation through HRM illustrate this well: by objectifying the employee and working the objectified image of the employee into the employees' self-understanding, they show how HRM not only help the employer but also the employee relate to and govern herself as a property (a human resource) with specific capacities to act as an autonomous employee.

Neoliberal governmentality, by contrast, draws on Hayek's (1976) and Friedman's (1982) view that individuals are not naturally inclined to compete and pursue their self-interest rationally in accordance with a market logic, yet, that it is for this very reason essential that they are made up as such. Government thus becomes a matter of artificially constructing markets and making up individuals fit to live in and through them. This implies that the role of the state changes from that of passively protecting the economic rationality of the market while compensating for its social ills, to that of resolving social ills (ill-health, dependency, etc.) by actively instituting the economic rationality of the market (Donzelot 2008; Foucault 2009). The view that individuals are autonomous to the extent that they own themselves as properties is still an essential part of neoliberal governmentality. Yet, the properties individuals own are not so much their capacities to carry out specific labour as their capacities to function as businesses (Gershon 2011). Conceived as a business the individual emerges as 'a collection of assets that must be continually invested in, nurtured, managed, and developed' (Martin 2000, 582). Furthermore, these assets and the investments and managerial attention they require no longer concern merely the individual's professional self and professional life, but her whole self and whole life. That is, whereas the liberal view of the autonomous individual as a capable labourer implies a distinction between the individual as worker/employee and the private individual and, in turn, a distinction between the individualistic principles of the economy and the solidary principles of civil society, the neoliberal view of the individual as an entrepreneur/business implies a generalization of the logic of the market and competition to virtually all spheres of life communities, families and individual lifestyles (Becker 1962; Brown 2006; Foucault 2009).

It is, I suggest, in relation to these transformations that we can position the observations referred to above as a 'lifestyle approach' (Kuhn 2006) or a 'just be yourself' approach to management (Fleming and Sturdy 2011). Such observations suggests a shift towards a neoliberal governmentality where individuals' personalities, lifestyles and social relations are seen as potential resources, but also as potential risks that should be managed and cared for in the sense of a business.

As is well known, it is in relation to these governmental transformations that the disciplinary regulation of schools, factories, bureaucracies, etc., begins to be criticized in the 1980 s for stifling the 
enterprising spirit of individuals' and organizational units (Dean 1995; DuGay 2004). Yet, according to Foucault (2007), the genealogy of this critique is much older, dating back to the dawn of the liberal era. Discipline, says Foucault, is in one sense not modern 'but completely archaic, since the panoptic mechanism involves putting someone in the centre ... who will be able to make his sovereignty function over all individuals placed within this [disciplinary] machine of power' $(2007,66)$. With the development of industrial towns and regions liberal thinkers begin to criticize discipline for the way it restricts individuals' liberties and prevents individuals and activities from being organized in open and expanding circuits. It is in the wake of this critique, means Foucault (2007) that partly new 'bio-political' forms of regulation emerge. These combine developments in the life sciences - medicine, psychology, eugenics and demography - with liberal economic values (see Dean 2015; Lakoff 2015; Rose 2007; Villadsen and Wahlberg 2015).

While bio-political and disciplinary regulation are both based on expertise and its associated abilities to observe and objectify individuals and populations, they differ in that discipline, says Foucault $(2007,44)$ 'is essentially centripetal ... [it] functions to the extent it isolates a space ... it concentrates, it encloses, it is protectionist' and seeks on this basis to help individuals correct and better themselves in relation to demarcated norms and ideals of proper conduct. Bio-political regulation, on the other hand, is centrifugal; it does not restrict and regulate a particular space, but seeks instead to influence the milieu in which individuals live and work; it determines individuals' specific lines of interest, the risks they confront given their sex, age, line of occupation, and so on, so that specific opportunities (education, counselling, etc.) can be offered that help individuals develop while evading risks. Important to note here is that in Foucault's view (2007), the difference between disciplinary and bio-political regulation is not simple and clear cut. Both concepts refer to forms of power that produce rather than restrict individuals' subjectivity. Yet, whereas discipline produces subjects (through the internalization of a regulative gaze) within controlled space/time domains (prisons, workplaces, schools, hospitals, etc.), bio-political regulation produces subjects in relation to broader ways of living and social activities that have been considered as secondary, reproductive domains for major institutions (Fleming 2014). Hence, while discipline seeks to contain the subject of power, bio-political regulation seeks to utilize its inherent and unlimited qualities by targeting individuals in their existing reality, trying to make that reality and its different components function better in relation to one another.

Rose (2007) has shown how the turn to neoliberal governmentality has altered bio-political regulations in two specific senses: While they remained until the late 1970 s closely connected to the state through systems of state funded social security and health care, the turn to neoliberal governmentality has gradually 'released' them from the direct control of the state and instead subjected them to market principles. Bio-political expertise marketed by competing firms is now something individuals chose either as private consumers or as employees being offered bio-political expertise (e.g. WHP programmes) by their employers. Furthermore, while bio-political regulations remained until the late 1970s closely connected to the liberal ambition of protecting individuals and civil society from the social injustices and health issues associated with the functioning of the market economy, they have since then, not the least through their marketization, become tied to the neoliberal ambition of remedying social injustices and health issues by helping individuals govern themselves in accordance an economic rationality (Villadsen and Wahlberg 2015).

The study of WHP presented below is intended as an example of a neoliberal bio-political regulation (henceforth post-disciplinary regulation). As such, the study relates directly to the sociological research referred to above that studies health initiatives as exemplars of neoliberal governmentality and post-disciplinary regulation (see e.g. Fullagar 2002; Lakoff 2015; Villadsen and Wahlberg 2015). Yet, this research has primarily studied changes in the government of public health (e.g. Lakoff 2015; Villadsen and Wahlberg 2015), specific changes in the organization of the health care sector (e.g. Ferlie, Mcgivern, and FitzGerald 2012; Prince, Kearns, and Craig 2006), or changes in the government of specific health issues such as alcoholism (Valverde 1996), psychosomatic illness (Greco 1993) or herbal medicine (Wahlberg 2006). Little interest has been devoted to health initiatives such as WHP that operate precisely at the intersection between work and life. That is, at the intersection where 
concerns for individuals' health encounter concerns for individuals' work performances. Given that this sociological strand suggests a defining characteristic of the new post-disciplinary orientation to health is its ambition 'to optimize life in accord with ... the existence of individual free enterprise' (Dean 2015, 19), WHP, as will be seen, emerges as a principal example, which should be of interest not only to researchers of organizational control, but also to researchers post-disciplinary forms of governing health.

\section{From 'healthism' to WHP: from liberal to neoliberal governmentality}

A basic premise of WHP is precisely that there is no necessary conflict between employees' health and employers' pursuit of efficiency (Zoller 2003). Quite the contrary, according to proponents of WHP (e.g. Ziglio, Simpson, and Tsouros 2011), investments in WHP convey promises of increasing organizational efficiency. In this respect, it is not surprising that WHP has received a lot of attention among representatives of big capitalist firms, among neoliberal reformers and among the professional middle and upper middle classes during the last 20 years (Maravelias 2009; McGillivray 2005; Zoller 2003). More surprising is that WHP's origin can be traced back to the 'healthism movement', a branch of the 1960s environmental movement located at the far left of the political spectrum (Crawford 1980). The healthism movement was an attack on scholastic medicine, which was seen to be an ally of corporate capitalism and economic liberalism (Crawford 1980; Korp 2007). By sticking to its narrow focus, treating individual's ill-health while disregarding the social-material context where, allegedly, the causes of ill-health were to be found, scholastic medicine was alleged by proponents of healthism to help corporate capitalism and the liberal political establishment disguise the injustices and social irrationalities of late modern capitalist societies. In this regard, the healthism movement established a radical but nevertheless typical critique of a liberal governmentality; ill-health should not be seen or treated as an individual problem, but as a social problem reflecting social inequalities and injustices caused by industrial capitalism (Lupton 1995).

Yet, healthism was not just a critique; it was also a social movement offering individuals a path to an allegedly better and healthier life. As such, healthism suggested that individuals should not passively subordinate to medical authorities (and thereby indirectly to state and capital). Instead they should be active in taking care of their own health and wellbeing (Crawford 1980). Hence healthism saw health as intertwined with individuals' liberation from dependency upon medical authorities, state and capital, a liberation, which ultimately was based on individuals' self-governing abilities and motivation.

Hence, while healthism's critique was a typical expression of a liberal governmentality, the solution it offered was not. This is not to say that the way of life that healthism suggested reflected a neoliberal mentality of rule. Yet, despite its anti-capitalist origin, it was this emphasis of individual agency and responsibility that opened up an interest for the healthism movement among advocates of neoliberal reforms (Crawford 2006; Korp 2007). More specifically, the professional middle classes, who, after 30 years of unbroken stability and progress, began to experience that their class positions were threatened in the late 1970s, saw in healthism's emphasis of autonomy, self-control and self-improvement a way of distinguishing their ethical superiority over the lower working classes. Furthermore, private corporations as well as neoliberal reformers saw in healthism not only a way of battling work related health costs, but also a way of shifting focus in the search for the causes and responsibilities of illhealth; from the employer and the conditions surrounding work to the individual and the lifestyle the individual choses. Finally, in the 1980s, when neoliberal reformers began to 'release' medical experts from the direct control of the state, subordinating them instead to the laws of the market, the burgeoning interest in healthism among private corporations and the professional middle classes emerged to parts of the medical expertise as a business opportunity which could be capitalized on (Lupton 1995).

It is here, at the intersection between private corporations, the professional middle classes and commercialized medical experts that WHP is born. It is born in the form of a co-optation of 
healthism's practical emphasis of individual self-control and responsibility and a disregard for its' political-economic critique (Crawford 2006).

This genealogy can be sensed in the World Health Organization's definition of WHP: 'WHP focuses on ... the promotion of healthy lifestyles' and involves 'the process of enabling employees to increase control over their health and its determinants' $(2005,1)$. Hence, WHP concerns employees' abilities of self-controlling their lifestyles. Furthermore, 'self-control' is not only seen as an instrument that leads to health; it is seen as an expression of health (Bunton and MacDonald 1992). All other things equal, the self-controlling individual is seen to be healthier than the individual that lacks self-control.

The short account above for the genealogy of WHP suggests how it is an expression of and an instrument in a transformation from liberal to neoliberal governmentality. Through accounts for WHP at Bus and Biotech, I attempt to show how WHP is also an example of post-disciplinary form of regulation.

\section{Methods}

Drawing on Foucault's notion of power/knowledge (e.g. 1977) I have analysed WHP as a form of power that operates through the expertise of health professionals. Not however in the sense of a resource that a health expert possesses and makes use of to regulate employees in particular ways. Rather, I have analysed WHP as a chain of discursively mediated practices where health experts are strategic links through their privileged access to 'truths' about health and wellbeing, but where employees, through their free participation and provision of knowledge about themselves and their lives, and managers, through their privilege to determine what is efficient and necessary principles of work and organization, are also involved in giving specific form and content to WHP. Hence, I understand WHP as a vehicle of power, but not because it enables health experts and managers to regulate the behaviour of employees, but because it operates as a 'technology of the self' (Rose 1996), that is, a technology that enables individuals to constitute themselves in relation to ideals of health and work.

The account below concerns two large international corporations referred to as Biotech and Bus. Biotech discovers, develops, manufactures and markets prescription medicines. It is active worldwide, employs more than 50,000 people and invests over $\$ 4$ billion in $R \& D$ each year. The account concerns one of Biotech's research centres located outside Stockholm, Sweden, which employed almost 1000 graduated researchers at the time of the empirical study (2010-2011). Bus develops, produces and markets Buses and trucks, operates worldwide and employs around 30,000 employees. The account concerns Bus's largest production facility outside Stockholm that employed 6000 bluecollar and 1000 white-collar employees at the time of the empirical study.

The reasons these two companies were chosen for the study was that they had invested considerable resources in building up internal health organizations that develop and provide WHP; that they were willing to participate in the study and interested in its results; and that the two companies together made it possible to study WHP in relation to two in part contrasting groups of employees, factory workers and biotech researchers.

The concern with WHP as a vehicle of power/knowledge was addressed by means of an ethnographic approach based on a combination of field observations and in-depth interviews. The study was divided in two partially separate foci. One part of the study primarily sought to gain an understanding for the two companies' core work activities, how they were organized and what types of demands they put on employees. Core concerns here were what the different groups of employees and managers at the two companies considered to be basic problems related to existing work procedures. In that connection I also studied how these experienced problems related to the characteristics of the employees and to the investments the two companies had made in WHP. For this part of the study 7 human resource managers, 18 shop floor supervisors and line managers, 31 workers and 16 persons in various staff functions at Bus were interviewed. At Biotech four human 
resource managers, seven researchers and three senior managers were interviewed. At Bus the daily work procedures of several factory teams were also observed.

The second part of the study focused explicitly on WHP programmes. Twenty-three interviews were carried out with health experts working at Bus's health organization and 20 with health experts working at Biotech's health organization. These were health coaches, psychologists, physiotherapists, ergonomists, medical doctors, work environment engineers and managers of the health organizations. The interviews focused on concrete aspects of the health professionals' work such as what kind of health-promotion programmes they offer; what the health experts and the employees expect from these programmes; how the programmes are organized; the strategies and goals of the health organization, and so on.

\section{WHP - the need for new (ways of managing) employees}

Both Bus and Biotech have invested considerably in WHP during the last 10-15 years. Biotech employs approximately 75 and Bus almost 200 health specialists. The incentives to invest in WHP differ between the two companies. For Biotech, the catalyst of the investments in WHP was its merger with another international Biotech company in the late 1990s. The merger led to a geographical dislocation of the research projects. Before the merger the projects were handled by researchers all of them working at the research facilities south of Stockholm. After the merger researchers working at different research facilities throughout the world handled the projects. A Biotech researcher explained:

One person may be located in London, the other in Stockholm, the third in New York and the fifth in New Deli. Can you imagine how difficult it is to schedule [video] meetings? I mean, when the guy in New Deli is about to have dinner with the kids, the guy in New York has just left his kids at the day care centre.

These geographically scattered working conditions resulted in that many researchers began to experience stress problems and/or problems of balancing work and private life. Investing in WHP was a direct reaction to these problems. Through WHP Biotech would provide its researchers with expertise that could help them govern their work and their lives to cope better with stress.

The catalyst for investing in WHP at Bus was different from that of Biotech. It related to problems that began to emerge in the mid-1990s when Bus initiated a mayor transformation of its principles of production from 'Taylorism' to 'Lean'. Lean was supposed to 'increase production quality while reducing personal turnover and sickness absenteeism', said a manager of production. Yet, implementing lean proved more difficult than initially expected. 'A basic reason for this', said a team leader 'is that Lean requires a new type of worker'. The head of Bus's production elaborated on this point: He said:

The crucial issue when implementing Lean has not been employees' skills but their mindsets. We can recruit individuals with appropriate technical skills or, if they lack particular skills, put them in training. But to make sure that our employees have the mindset that makes them up to the challenges that come with Lean has proved to be a lot more difficult.

The worker with a suitable mindset, said one of the team leaders

... is pragmatic and social; he is not an analyst trying to find the best solution to everything, but neither is he passive and unreflective, waiting for someone to tell him what to do. He is doer, but a doer that reflects upon what he does and wants to make it better.

What has this got to do with WHP? With its focus on motivating employees' to improve their lifestyles in the direction of more self-control and activity, WHP gradually emerged 'as a way of improving employees' health while improving their fitness for Lean' said the head of WHP at Bus. The problem when implementing Lean had not been possible to restrict to employees' lack of specific professional competencies, but concerned employees' lifestyles and personalities. Here, WHP came forth as an instrument, which could help Bus link aspects of employees' lives and personalities to Bus's productive activities. 
On the one hand, Biotech's problems and incentives to invest in WHP were the opposite of those of Bus. What gave Biotech problems was not its researchers' lack of self-control and lack of ambition of improving in work as well as in life more generally. It was the fact that its researchers were too keen and able, as it were, to act precisely in that regard. The researchers tried to be good parents, good husbands and wives, appreciated colleagues and careerists, all at once. Sometimes this just amounted too much stress and a lack of balance between private and professional concerns.

On the other hand, however, Biotech's problems and incentives to invest in WHP were very similar to those of Bus. Underneath the surface the problem was not that of reducing stress, it was that of developing in the researchers a mindset and a set of skills that made them able to self-govern their lives, careers and the relations between them efficiently, without arousing too much stress.

In this sense, both companies saw WHP as a form of conduit to what Kuhn (2006) refers to as a 'lifestyle approach' to management. That is, they used WHP both as a way of opening up work to highly personal and private matters and as a way of letting those private and personal matters be structured by the performance logic and premises of work. Yet, in which regards did WHP hereby break with disciplinary principles of regulation? Through the account below for the WHP programmes of the two companies, I will attempt to answer this question.

\section{WHP - managing lifestyles}

The basic organization of WHP activities is similar in both companies. So-called multi-professional teams comprising a health coach, a psychologist, a physiotherapist, an ergonomist, a work environment engineer and a medical doctor establish the basic WHP units. Each team is responsible for promoting the health of a limited section of the two companies' personnel. The teams' main focus is not the employees' working conditions, but their lifestyles. To underline the importance of this focus Bus has formalized a so-called ' 24 hour employee' policy. The head of WHP said:

It is meant to remind employees that Bus cares for them even when they are not working. Yet, it is also meant to remind employees that they have a responsibility to take care of themselves to stay healthy and fit for work.

Employees' lifestyles are thus more or less explicitly seen as assets that require management. How does WHP help employees manage their lifestyles as assets? The basic premise of well-functioning WHP activities, said a health expert at Biotech is to maintain a 'database about the employees'. At both companies statisticians assist the teams in this work. One of the statisticians said that:

We help to categorize employees with regards to their line of work, age, sex, marital status, whether or not they have children, eating and drinking habits, the extent to which they exercise, what type of problems they have had physically or psychologically, and so on.

Noteworthy here is that apart from the fact that focus is not on employees' professional competencies and behaviour, but their private characteristics and behaviour, WHP does not divert much from for instance Townley's (1994) outline of HRM as an example of disciplinary regulation of employees. Just like HRM, WHP is based on the possibility of examining employees, thus turning them into objects of knowledge and management. Data primarily comes from yearly health screenings, sickness absenteeism reports and previous attendances in WHP programmes. Based on the wide spectrum of knowledge that the teams and statisticians accumulate about the employees, specific WHP programmes are put together for those employees that 'want to participate and have shown signs of potential ill-health' said a physiotherapist at Bus.

As indicated above, the WHP programmes that Biotech offers its research employees are primarily geared towards stress management and work-life balance whereas the WHP programmes that Bus offers its workers are primarily geared towards lifestyle change. Yet, the programmes at Biotech and Bus share the same basic three step structure. The first step involves a series of meetings with a health expert and is meant to help the employee understand and accept responsibility for the employee's health issue. A health expert at Bus explained that: 
Many clients initially place their health problem outside themselves. If they have a weight problem they say that they have not got the time to exercise or that the problem is genetic. We try to turn that around. We want them to see and accept that they have a choice and that the problem and solution lie within themselves.

In a similar vein a health expert at Biotech meant that:

Initially, many of our clients complain about their workload, how hard it is to cope especially if one has a family that also needs ones attention and care. While I do understand these complaints I cannot do much when it comes to changing the work conditions - none of us can. What we can do, however, is to help the clients cope better with the challenges of both their work and private life. The first step is then to make the client commit to and believe that they will gradually learn how to deal with things.

As these quotes make clear, the health experts do not protect clients against health risks or treat them for the ill-health they have acquired. Instead they act as coaches that try to develop clients' abilities of self-managing these health risks.

The second step revolves around mapping out and discussing the daily routines of the employee. This step is then meant to make the employee's lifestyle explicit, revealing its strengths and weaknesses and those activities that the employee finds motivating and those she finds hard to do. A health expert at Biotech said that

Just this morning I met a typical client, very ambitious and highly qualified. She has two kids at home, both playing tennis and football, and a husband who also has a demanding job. I let her describe her daily routines, nothing spectacular, just how the days proceeds, what she likes, does not like, is stressed about and so on. It may not seem very sophisticated, but to be able to change yourself and the way you do things, you need to know who you are and you need to be able to see and control what you do on a daily basis.

A health expert at Bus complemented this view by pointing towards the importance of finding out about those things in a client's life that he or she really likes and is motivated by.

He said:

You go through the small things clients do every day; how they get to work, when and how they pick up the kids, and so on. As you go through these things with the client you try to find out if there are certain things that the client is really good at and likes to do. For instance, if a client likes to go for long walks you note that; because WHP is all about finding the good things clients do and trying to make them do more of them.

The third step revolves around helping the employee establish new routines and ultimately a more active lifestyle, which, as the last quote illustrates, is grounded in the employee's already existing faculties and routines. An employee 'with a slight weight problem' at Bus explained:

When I entered the program I was afraid that most of my life would be disqualified. Yet, no one has tried to change me from the ground up. It is about the little things, e.g. the fact that I like to go mountain biking or that I happen to like to eat fish.

The last quotes let us sense in which respects WHP differs from a disciplinary approach. WHP focus on improving employees rather than changing them. It attempts to find employees' inherent qualities and promote them. A physiotherapist at bus explained:

We do not try to develop supermen and women. We do not say: 'this is what you should do, this is who you should be'. We just try to help employees find their potential and help them develop it.

An employee at Bus illustrated this point:

I have thought about becoming a spinning instructor, but you know, I never did anything about it ... . The health experts find out about those dreams and they push us to do something about them. You know, by being more conscious about what we do, not trying to do a little bit of everything, but committing to something in particular, investing our efforts sensibly, setting goals, following up on those goals and so on.

The statement illustrates not only how employees are helped to find their potential, but also how they are helped to develop it by adopting a strategic mindset towards work and private life. 'That is the mind-set that we want our clients to adopt', said a health expert, and continued: 'They should feel that their lives are the results of their choices, not of coincidences or of forces beyond their control'. 
At these points, the WHP programmes at Biotech differ most significantly from those at Bus. As recalled, at Biotech the problem is not the researchers' lack of accountability, lack of self-consciousness and lack of a strategic mindset, but on the contrary, the fact that the clients tend to be too advanced in these regards. A health expert explained:

Most of our clients are extremely ambitious and conscious about everything they do. It is not just that they try to stay up front in their areas of research; they try to stay up front in all areas of their lives. They are keen on and conscious about giving their kids the best possible start in life, keen on taking care of their marriage, keen on keeping fit, and so on. While all of this can be seen as good things, it is difficult to keep them all up at the same time. Very often this is actually the basic problem we try to help them with.

Hence, the clients are explained to be so conscious and controlling of their lives that they lose their oversight and control. The result of this is stress and a failure to balance work and private life. One of the clients said that:

The program has helped me in two ways. It has helped me see how much I actually do and in a sense how much I achieve both professionally and privately. It has also helped me realize that everything is not up to me and that that this is actually a good thing. Because when you accept that you tend to relax a bit.

Hence, by going through and mapping the details of their private and professional lives the clients are helped at once to oversee and control the different parts of their professional and private lives and to let go of some of their inclination to control themselves and their lives. While the purpose was more control and thus less stress and a more sustainable balance between work and private life, the way to get there was, somewhat paradoxically, to let go of some control.

\section{Critical voices and resistance}

Most employees that had participated in the WHP programmes at Bus and Biotech were positive towards its effects. Yet, there were also critical voices. An employee at Bus said:

To fit in at Bus you do not have to be anything special. ... But, you have to want to improve. ... It seems to be the defining feature of ... everything that is good in a person. So if you lack motivation, what are you then? A bad person, ill or what?

Employees as well as health experts, both at Bus and at Biotech, touched upon this issue: WHP did not attempt to mould employees' lifestyles in relation to a predetermined plan, but it did convey the risk of making employees' lack of motivation a moral deficit or, possibly, a medical problem. For instance, a health expert at Bus stated that:

WHP is something you can choose to disregard, but only as long as you meet the requirements of work. For instance, if an employee that is overweight starts having problems of keeping up with his work because the tempo is getting higher and higher, then he might be diagnosed as having a weight problem. Sure, he can still choose not to participate in WHP, but that will eventually lead to that he is defined as having reduced work abilities, which in turn might lead to that he loses his job.

In a similar vein a participant of one of Biotech's WHP programmes said that:

Demands keep getting higher and higher. And when they eventually get so high that you cannot fully keep up any longer, well then you have a stress problem and are offered a stress program. If you still do not cope, than that will be taken as a sign of that you should perhaps seek another more suitable job.

Another former participant of WHP programmes at Biotech explained that:

The health experts promote those parts of your life that they define as valuable - coping, choosing, committing, improving, etc. In a way health thereby becomes a performance next to other performances.

In general the account points towards a few principle ideas that underlie WHP at both companies: First, the idea that health is not primarily a bio-medical condition that you are, or are not, gifted with, but an active choice, responsibility and performance, which is rooted in your lifestyle. Third, 
the idea that health is inescapably intertwined with motivation. Finally, the idea that health is an investment, that is, a long-term commitment that requires self-discipline and an assessment of ones' natural strengths and weaknesses that may eventually pay off in the form of even better health, wellbeing and work performances.

These ideas underlie programmes that, as we have seen, do not seek to protect employees from demanding working conditions, but seek to help employees cope with them. Furthermore, in this pursuit they do not attempt to change or correct employees in accordance with precise criteria of a healthy life, but tries instead to find among the activities, routines, skills and inclinations that make up their present (and sometimes past) lifestyles those which are worth promoting so that others, which are not, resides into the background or disappear altogether.

\section{Discussion and conclusions}

Through the study of WHP this paper has aimed to provide an example of a post-disciplinary form of control focusing on employees' lifestyles as assets or indeed as 'human capital' (Becker 1962; Schultz 1971). In this final section I will use the account to develop the distinction between disciplinary and post-disciplinary forms of control.

Discipline, says Foucault (Foucault 2007, 58) circumscribes and isolates a space (e.g. the workplace) where the individual knows that she is always potentially seen, always potentially caught misbehaving so that she gradually understands that it is best to internalize 'the disciplinary code of the permitted and the forbidden'. Covaleski et al.'s (1998) study of accounting firms is a good example. They show how a combination of management by objectives and mentoring establish among employees a sense of being continuously examined and evaluated at work. This, mean Covaleski et al. (1998), leads employees to gradually internalize corporate goals and language and design themselves as 'corporate clones', acting autonomously in accordance with corporate values and norms.

The WHP programmes at Buss and Biotech display features, which depart considerably from this disciplinary grid. First of all, WHP focuses on employees' conduct in the open and unregulated sphere of their lifestyles. Employees' lifestyles are not treated as spaces to be regulated and fixed by WHP, but as milieus of more or less unforeseeable events, which WHP seeks to influence, on the one hand, by offering a range of resources and opportunities geared to promote a particular conception of a healthier and better life, and on the other hand, by appealing to employees' desire to use these opportunities and resources to better themselves.

Here we touch upon a second principal difference. Discipline typically starts by positioning ideals that it subtly imposes on a specific secluded reality (Foucault 1977). Furthermore, it is exhaustive in the sense that it seeks to inject prescriptive norms into individuals' conduct that lead them towards acting appropriately at every moment (Foucault 2007; Munro 2012). Kunda's (1992) study of 'cultural engineering' at a high-tech corporation is here a typical example. The cultural engineering programme makes the firm a relatively closed system that idealizes employees who see the firm as their 'family' and are ready to modify themselves to fit its' clan-like features. 'You keep that shit to yourself' (Kunda 1992, 203), explained one of the employees, when asked about personal opinions and inclinations that do not fit corporate ideals.

WHP, by contrast does not strive to divide employees' conduct in terms of what is correct or incorrect, permitted or forbidden. In fact, it seeks to avoid specifying absolute standards and ideals, which restrict individuals' freedom of movement and reduce their motivation; it is more interested in that individuals are active than in which specific regards they are active. As stated in the introduction, WHP is in these regards closely associated with the 'just-be-yourself' orientation to control that for instance Fleming and Sturdy (2011) and Kunda and Ailon-Souday (2005) have found among contemporary organizations (see also Kuhn 2006; Munro and Weiskopf 2011). Rather than an ambition of adapting employees to pre-defined normative ideals that should turn them into 'appropriate employees' (Alvesson and Willmott 2002) or 'corporate clones' (Covaleski et al. 1998), Fleming and Sturdy (2011) and Kunda and Ailon-Souday (2005) suggest that contemporary organizations seek to 
foster employees who work enthusiastically and creatively precisely because they link their whole selves to productive activities.

The account for WHP relates directly to these observations. On the one hand, in that WHP idealizes employees that do not seek to subject to norms of appropriateness, but employees that seek to commit to aspects of their existing selves and lifestyles which they can render useful. On the other hand, in that WHP emerges as a programme that is explicitly devised to make up such employees. As we have seen, WHP tries to help employees cope with the existing conditions of their work and private lives in all their divergences and varieties. First, by charting them up, rendering them into objects of management that can be arranged and dealt with in a planned and rational fashion by the employees themselves; then by defining and promoting employees' unique strengths, that is to say, already existing faculties and activities that are aligned with a 'good and healthy life' and that the employees are motivated by; finally, by aligning their private and professional lives, not however by turning their private and professional lives into seamless wholes, but by teaching the employees to manage their private and professional lives on the basis of one uniting moral principle, that of a continuous striving for improvement, be it in the form of health, happiness or professional success. Hence, as opposed to discipline, WHP is prescriptive and idealizing only in one specific regard; it takes it as a fact that a good, healthy, efficient and even a happy life is a self-managed life, a life which is actively chosen, informed and geared towards improvements.

Hence, both Kunda's (1992) study of corporate culture and Covaleski et al's (1998) study of management by objectives and mentoring reflect a disciplinary regime of control where employees' private selves stand in the way of organizations' ambitions of disciplining employees in relation to corporate ideals (see also Knights and McCabe 2003; Thomas and Davies 2005). WHP, by contrast, does not seek to impose ideals and norms, which establish a distinct boundary between work and life. It seems to be based on the conviction that since the disciplinary ambition of changing individuals is difficult, costly and sensitive, it is more efficient and less obtrusive to regulate employees on the basis of who they are already, what they like to do and know how to. While the centripetal logic of discipline is paradoxical in that it tries to profoundly change individuals so that they fit precise, restricted and unchanging norms of appropriate and good conduct (O'Malley 2000), the paradox of the centrifugal logic of the post-disciplinary approach found in WHP is that it tries to find and promote a stable existing core of individuals for the sake of rendering them useful in environments dominated by ideals of change and improved performance. It is in this respect that the post-disciplinary approach found in WHP is less a way of correcting individuals in relation to specific ideals than a way of helping individuals repackage and 'commodify' themselves as valuable human capital (cf. Becker 1962).

We thereby touch upon a third principal difference. Discipline, as noted, is related to a liberal governmentality, which idealizes individuals that are autonomous in the sense that they can relate to themselves as human resources with specific skills, which are valuable in specific forms of employment (Gershon 2011). WHP, however, is associated with a neoliberal governmentality, which idealizes individuals that are autonomous in the sense that they can relate to their whole self and life as collections of assets, which are valuable in relation to an entrepreneurial orientation to life as such (Gershon 2011). A basic condition of the neoliberal governmental orientation of WHP is the concept of health it is based on. As we saw, WHP understands health not merely as a bio-medically defined condition, but also as a particular attitude and lifestyle. In line with what has been found in sociological studies of neoliberal orientations to public health (e.g. Dean 2015; Lakoff 2015), WHP defines a healthy individual as a person that is self-conscious and responsible with regards to risks while active and positive with regards to opportunities to improve in all of life's spheres. It is on the basis of this view of health as a matter of optimizing 'life in accord with ... the existence of individual free enterprise' (Dean 2015, 19) that employees' lives and work emerge as strategically and seamlessly linked in WHP.

As we saw in the accounts above, this is expressed by the health experts' explicit emphasis that WHP presupposes that individuals maintain a strategic orientation not only to work but also to their lives in general. More fundamentally, it is expressed by the significance the health experts 
give to the expression 'the right mindset'. What characterizes a good promotable mindset? The account suggests that a good promotable mindset is one that is permeated by an economic logic of investment. This implies not only that an investment in a better diet or in improved abilities to handle stress is expected to pay off in the form of measurable improvements of one's general quality of life or in the form of professional success, but also that other areas, which are estimated and expected not to deliver such returns are subject to disinvestment. In other words, WHP is about promoting a mindset in employees that leads them to strategically prioritize those areas of their existing lives, which are expected to pay off so that others, which are not likely to pay off, are diminished or abandoned altogether. As such I believe it illustrates well what Foucault (2009) saw as the general principle of a neoliberal governmentality, namely its tendency of understanding life in total as an economic function.

It is here, at the point where WHP reveals its neoliberal face most explicitly, that WHP also comes closest to revealing its most authoritarian face. As recalled, Bus's ' 24 hour employee' policy implies, on the one hand, that the company should care about its employees also after working hours and, on the other hand, that the employee should care about leading a private life that enables him or her to come to work well prepared and capable. As long as employees handle their jobs properly, Bus cannot require that the employees in fact make use of the WHP facilities that it offers. If, however, a health expert can show that an employee's lifestyle is the cause of the employee's inability to successfully handle her job, the freedom to disregard WHP transforms into directives that the employee is required to follow to keep her job.

In this respect, the extent to which WHP comes forth as a technology dedicated to help employees freely fashion healthy and productive lives, or as a technology that subjects employees to authoritarian control is linked to employees' ability to act in accordance with general performance criteria. In other words, the individual's value as human capital is the fundamental criterion that determines the employees' freedom to disregard WHP. As such, WHP can be criticized along the same general lines as neoliberalism has been criticized: It is based on a restricted notion of freedom conceived as the right to pursue one's potential as human capital (cf. Bourdieu 2003). For those that lack the required potential, WHP is not just useless it also comes forth as a test demonstrating this lack of potential.

In conclusion, this paper has aimed to contribute to two lines of research. First and foremost the paper has aimed to contribute to research on unobtrusive controls, which operate through an ambition of regulating employees' identities (e.g. Alvesson and Willmott 2002; Covaleski et al. 1998; Kunda 1992; Knights and McCabe 2003; Thomas and Davies 2005; Townley 1994). More specifically it has aimed to contribute to this research in two respects. First, the majority of studies have focused on discourses and techniques such as corporate culture and HRM that hold on to and seek to maintain a relatively clear distinction between work and life. This paper, by contrast, has accounted for WHP to illustrate the relevance of also studying discourses and techniques, which focus on and seek to regulate non-work associates such as employees' lifestyles as important sources of organizational control. Second, via the concepts of neoliberal governmentality and post-disciplinary control the paper has developed an analysis of WHP that shows how ambitions of instrumentalizing employees' inherent non-work qualities can be analysed in ways that differ from the disciplinary framework that the majority of studies hold on to. More specifically, rather than as a potential extension of a managerial disciplinary gaze further out into the non-economic, social and private world beyond work, the instrumentalization of employees' inherent non-work qualities has emerged as a matter of doing away with the (liberal) distinction between a managed world of work and a non-managed world beyond work altogether. That is, WHP has come forth as an unobtrusive form of control that operates through an ambition of regulating employees' identities. Yet, it has not emerged as a form of expertise that seeks to discipline employees to freely strategize themselves in accordance with secluded corporate norms and ideals, but as a form of expertise that seeks to 'help' employees turn their lives into idiosyncratically managed capitals.

In that connection, the paper has suggested it is in those terms we should understand the observations reported in the studies mentioned above, which report that many corporations have come to 
idealize employees that are able to make use of their whole selves as corporate resources (e.g. Fleming and Sturdy 2011; Kuhn 2006; Kunda and Ailon-Souday 2005; Munro and Weiskopf 2011): As specific expressions of a general transformation to a neoliberal governmentality, which implies that the liberal distinctions between professional, private and social have begun to crumble. These studies explicitly or implicitly ask through which discourses and forms of control it is possible to make up employees who relate to their lifestyles, their distinctive attitudes and interests, their bodies, their social relations, etc., in ways that make them elements of their human capital? In developing how WHP operates as a post-disciplinary control, which links employees' lives to professional activity, I suggest this paper has taken steps towards answering that question.

Whilst operating on a different level of abstraction, the paper has also aimed to contribute to the two Foucauldian strands of sociological studies, which it has made use of to develop its conceptual framework: On the one hand, the works of for instance Dean (1999), McNay (2009) and Rose (1999), which have developed Foucault's works on neoliberalism in relation to the evolution of post-disciplinary techniques such as precarious employments, audit mechanisms and quasi markets. On the other hand, the works of for instance Lakoff (2015), Fullagar (2002), Rose (2007) and Wahlberg and Rose (2015), which have developed Foucault's works in relation to issues of public health, healthcare and the government of specific health issues. While the first strand has shown how post-disciplinary techniques differ from older forms of discipline through their ways of encouraging individuals to turn their lives into flows of human capital in the market place, the second strand has shown how new public health programmes and new ways of organizing healthcare make health a matter of optimizing life in accord with the logic of enterprise. Given that this paper has shown how WHP makes a healthy life a matter of living entrepreneurially, and an entrepreneurial life a matter of healthy living, I suggest it provides an example, which operate at the precise intersection of these two research strands.

\section{Funding}

This research was funded by Handelsbankens forskningsstiftelser research foundation [grant number P2015-0246:1].

\section{Disclosure statement}

No potential conflict of interest was reported by the author.

\section{References}

Alvesson, Mats. 2000. "Social Identity and the Problem of Loyalty in Knowledge-intensive Companies." Journal of Management Studies 37 (8): 1101-1124.

Alvesson, Mats, Karen Ashcraft, and Robyn Thomas. 2008. "Identity Matters: Reflections on the Construction of Identity Scholarship in Organization Studies." Organization 15 (1): 5-28.

Alvesson, Mats, and Hugh Willmott. 2002. "Identity Regulation as Organizational Control: Producing the Appropriate Individual." Journal of Management Studies 39 (5): 619-644.

Barker, James. 1993. "Tightening the Iron Cage: Concertive Control in Self-managing Teams." Administrative Science Quarterly 38: 408-437.

Barratt, Edward. 2008. "The Later Foucault in Organization and Management Studies." Human Relations 61 (4): $515-537$.

Becker, Gary S. 1962. "Investment in Human Capital: A Theoretical Analysis." The Journal of Political Economy 70 (5): 9-49.

Bergström, Ola, and David Knights. 2006. "Organizational Discourse and Subjectivity: Subjectification During Processes of Recruitment." Human Relations 59 (3): 351-377.

Bourdieu, Pierre. 2003. Firing Back: Against the Tyranny of the Market. London: Verso.

Brown, Wendy. 2006. Regulating Aversion: Tolerance in the Age of Identity and Empire. Princeton, NJ: Princeton University Press.

Bunton, Robin, and Gordon MacDonald. 1992. Health Promotion: Disciplines and Diversity. London: Routledge.

Collinson, David. 2003. "Identities and Insecurities: Selves at Work." Organization 10 (3): 527-547. 
Covaleski, Mark, Mark Dirsmith, James Heian, and Sajay Samuel. 1998. "The Calculated and the Avowed: Techniques of Discipline and Struggles over Identity in Big Six Public Accounting Firms." Administrative Science Quarterly 43 (2): $293-$ 327.

Crawford, Robert. 1980. "Healthism and the Medicalization of Everyday Life." International Journal of Health Services 10 (3): 365-388.

Crawford, Robert. 2006. "Health as a Meaningful Social Practice." Health: An Interdisciplinary Journal for the Social Study of Health, Illness and Medicine 10 (4): 401-420.

Dean, Michel. 1995. "Governing the Unemployed Self in an Active Society." International Journal of Human Resource Management 24 (4): 559-583.

Dean, Mitchell. 1999. Governmentality: Power and Rule in Modern Society. London: Sage publications.

Dean, Mitchell. 2015. "The Malthus Effect: Population and the Liberal Government of Life." Economy and Society 44 (1): 18 39.

Deetz, Stanley. 1998. "Discursive Formations, Strategized Subordination and Self Surveillance." In Foucault, Management and Organization Theory, edited by Allan McKinley and Ken Starkey, 151-172. London: Sage.

Donzelot, Jacques. 2008. "Michel Foucault and Liberal Intelligence." Economy and Society 37 (1): 115-134.

DuGay, Paul. 2004. "Against 'Enterprise' (but not Against Enterprise Because that Would Make no Sense)." Organization 11 (1): 37-57.

Ferlie, Ewan, Geryy Mcgivern, Louise FitzGerald. 2012. "A New Mode of Organizing in Health Care? Governmentality and Managed Networks in Cancer Services in England." Social Science and Medicine 74 (3): 340-347.

Fleming, Peter. 2014. "Review Article: When 'Life Itself' Goes to Work: Reviewing Shifts in Organizational Life Through the Lens of Biopower." Human Relations 67 (7): 875-901.

Fleming, Peter, and Andrew Sturdy. 2011. "'Being Yourself' in the Electronic Sweatshop: New Forms of Normative Control." Human Relations 64 (2): 177-200.

Foucault, Michel. 1977. Discipline and Punish. New York: Pantheon.

Foucault, Michel. 2003. Society Must be Defended: Lectures at the Collège de France. London: Picador.

Foucault, Michel. 2007. Security, Territory, Population: Lectures at The Collége de France, 1977-1978. London: Picador.

Foucault, Michel. 2009. The Birth of Biopolitics: Lectures at the Collége de France, 1978-1979. London: Picador.

Friedman, Milton. 1982. Capitalism and Freedom. Chicago, IL: University of Chicago Press.

Fullagar, Simone. 2002. "Governing the Healthy Body: Discourses on Leisure and Lifestyle within Australian Health Policy." Health - An Interdisciplinary Journal for the Social Study of Health, IIIness and Medicine 6 (1): 69-84.

Gershon, Ilana. 2011. "Neoliberal Agency." Current Anthropology 52 (4): 537-555.

Gordon, Colin. 1991. "Governmental Rationality: An Introduction." In The Foucault Effect: Studies in Governmentality, edited by Graham Burchell, Collin Gordon and Peter Miller, 1-52. Chicago, IL: University of Chicago Press.

Greco, Monica. 1993. "Psychosomatic Subjects and the 'Duty to be Well'. Personal Agency Within." Economy and Society 22 (3): 357-372.

Hayek, Friedrich. 1976. Law, Legislation and Liberty - The Mirage of Social Justice. New York: Routledge Keagan and Paul.

Knights, David, and Darren McCabe. 2003. "Governing through Teamwork: Reconstituting Subjectivity in a Call Centre." Journal of Management Studies 40 (7): 1587-1619.

Knights, David, and Hugh Willmott. 1989. "Power and Subjectivity at Work: From Degradation to Subjugation in Social Relations." Sociology 23 (4): 535-558.

Korp, Peter. 2007. "The Symbolic Power of Healthy Lifestyles." Sociological Review 17 (1): 18-26.

Kuhn, Timothy. 2006. "A 'Demented Work Ethic' and a 'Lifestyle Firm': Discourse, Identity, and Workplace Time Commitments." Organization Studies 27 (9): 1339-1358.

Kunda, Gideon. 1992. Engineering Culture: Control and Commitment in a High-tech Corporation. Philadelphia, PA: Temple University Press.

Kunda, Gideon, and Galit Ailon-Souday. 2005. "Managers, Markets and Ideologies - Design and Devotion Revisited." In The Oxford Handbook of Work and Organization, edited by Steven Ackroyd, Rosmary Batt, and Paul Thompson, 200-219. New York: Oxford niversity Press.

Lakoff, Andrew. 2015. "Real-time Biopolitics: The Actuary and the Sentinel in Global Public Health." Economy and Society 44 (1): 40-59.

Lazzarato, Maurizio. 2009. "Neoliberalism in Action: Inequality, Insecurity and the Reconstitution of the Social." Theory, Culture \& Society 26 (6): 109-133.

Lemke, Thomas. 2001. "The Birth of Bio-politics': Michel Foucault's Lecture at the Collége de France on Neo-liberal Governmentality." Economy and Society 30 (2): 190-207.

Lupton, Debora. 1995. The Imperative of Health: Public Health and the Regulated Body. London: Sage.

Maravelias, Christian. 2009. "Health Promotion and Flexibility: Extending and Obscuring Power in Organizations." British Journal of Management 20 (3): S194-S203.

Martin, Emily. 2000. "Mind-body Problems." American Ethnologist 27 (3): 569-590.

McGillivray, David. 2005. "Fitter, Happier, More Productive: Governing Working Bodies Through Wellness." Culture and Organization 11 (2): 125-138. 
McNay, Lois. 2009. "Self as Enterprise: Dilemmas of Control and Resistance in Foucault's the Birth of Biopolitics." Theory Culture Society 26 (6): 55-77.

Miller, Peter, and Nikolas Rose. 2008. Governing the Present: Administering Economic, social and Personal Life. London: Polity Press.

Mirowski, Philip. 2013. Never let a Serious Crisis go to Waste: How Neoliberalism Survived the Financial Meltdown. London: Verso.

Munro, lain. 2012. "The Management of Circulations: Biopolitical Variations After Foucault." International Journal of Management Reviews 14 (3): 345-362.

Munro, lain, and Richard Weiskopf. 2011. "The Management of Human Capital: Discipline, Security and Controlled Circulation." Organization 20 (1): 1-18.

O'Malley, Pat. 2000. "Uncertain Subjects: Risks, Liberalism and Contract." Economy and Society 29 (4): 460-484.

Prince, Russell, Robin Kearns, and David Craig. 2006. "Governmentality, Discourse and Space in the New Zealand Health Care System, 1991-2003." Health \& Place 12 (3): 253-266.

Rose, Nicolas. 1996. Inventing Ourselves: Psychology, Power and Personhood. Cambridge: Cambridge University Press.

Rose, Nicolas. 1999. Powers of Freedom: Reframing Political Thought. Cambridge: Cambridge University Press.

Rose, Nicolas. 2007. The Politics of Life Itself: Biomedicine, Power and Subjectivity in the 21st century. Princeton, NJ: Princeton University Press.

Schultz, Theodore. 1971. Investment in Human Capital: The Role of Education and of Research. New York: Free Press.

Sewell, Graham, and Barry Wilkinson. 1992. "Someone to Watch Over me': Surveillance, Discipline and the Just-in-time Labour Process." Sociology 26 (2): 271-289.

Smith, Adam. 1977/1776. The Wealth of Nations. Chicago, IL: University of Chicago Press.

Thomas, Robyn, and Annette Davies. 2005. "Theorizing the Micro-politics of Resistance: New Public Management and Managerial Identities in the UK Public Services." Organization Studies 26 (5): 683-706.

Townley, Barbara. 1994. Reframing Human Resource Management: Power, Ethics and the Subject at Work. London: Sage.

Valverde, Mariana. 1996. "'Slavery from Within': The Invention of Alcoholism and the Question of Free Will." Social History 22 (3): 251-268.

Villadsen, Kaspar, and Ayo Wahlberg. 2015. "The Government of Life: Managing Populations, Health and Scarcity." Economy and Society 44 (1): 1-17.

Wahlberg, Ayo. 2006. "Bio-politics and the Promotion of Traditional Herbal Medicine in Vietnam." Health 10 (2): $123-147$.

Wahlberg, Ayo, and Nikolas Rose. 2015. "The Governmentalization of Living: Calculating Global Health." Economy and Society 44 (1): 60-90.

WHO. 2005. "The Bangkok Charter for Health Promotion in a Globalized World." http://www.who.int/healthpromotion/ conferences/6gchp/bangkok_charter/en/.

Willmott, Hugh. 2005. "Theorizing Contemporary Control: Some Post-structuralist Responses to Some Critical Realist Questions." Organization 12 (5): 747-780.

Ziglio, Erio, Sarah Simpson, and Agis Tsouros. 2011. "Health Promotion and Health Systems: Some Unfinished Business." Health Promotion. International 26 (2): 216-225.

Zoller, Heather. 2003. "Working Out, Managerialism in Work Place Health Promotion." Management Communication Quarterly 17 (2): 171-205. 